\title{
BLEVE Overpressure: Multiscale Comparison of Blast Wave Modeling
}

\author{
D. Laboureur, ${ }^{a}$ F. Heymes, ${ }^{\text {b }}$ E. Lapebie, ${ }^{c}$ J.M. Buchlin, ${ }^{a}$ and P. Rambaud ${ }^{a}$ \\ von Karman Institute, Rhode-St-Genèse, Belgium; laboureu@vki.ac.be (for correspondence) \\ ${ }^{\mathrm{b}}$ Ecole des Mines d'Alès, 30319 Alès, France \\ ${ }^{c}$ CEA, DAM, GRAMAT, F-46500 Gramat, France
}

BLEVE overpressure modeling has been already widely studied but only few validations including the scale effect have been made. After a short overview of the main models available in literature, a comparison is done with different scales of measurements, taken from previous studies or coming from experiments performed in the frame of this research project. A discussion on the best model to use in different cases is finally proposed.

Keywords: BLEVE; blast wave; overpressure modeling; supercritical

\section{INTRODUCTION}

The most dangerous accident that can occur in pressure vessels is the boiling liquid expanding vapor explosion (BLEVE). The BLEVE is defined as an explosion resulting from the failure of a vessel containing a liquid at a tempera-ture significantly above its boiling point at normal atmos-pheric pressure (CCPS 2010 [1]). BLEVE accidents appear mostly when the vessel is engulfed by fire. The heat increases wall temperature and internal pressure and induces wall-thinning, fissures, or reduction of the mechanical strength. The vessel then fails; vapor is ejected and the fluid boils rapidly due to the pressure drop. BLEVE phenomenon has major consequences: generation and propagation of a blast wave, fragment projection, and formation and evolution of a fireball if the fluid contained inside the vessel is flammable.

Looking more deeply into the blast wave models, diverse methods have been proposed in literature to estimate the overpressure caused by pressure vessel explosions. The objective of the article is to compare these models with the experimental data existing in the literature, following a previous study [2]. Small scale experiments are also performed and show that, for this scale of vessel, the fluid can become supercritical before rupture. Therefore, the previous models predicting the overpressure need to be adapted for supercritical BLEVE. After a literature survey on blast wave generated by a BLEVE and the available models in literature, a compar-ison at large, mid, and small scales will be performed, using experiments from literature but also results of a small scale experimental campaign carried out in the frame of this project.

\section{BLEVE OVERPRESSURE PREDICTIONS}

\section{Blast Wave Produced by a BLEVE}

When a pressure vessel ruptures, the rapid expansion of the vessel content produces a blast wave. A blast wave is a transient change in gas-dynamic state parameters like pressure, density, and particle velocity. For a gas-filled vessel rupture, the blast wave pressure at a fixed reference distance shows an initial peak, followed by a negative phase, and a second peak develops due to an over-expansion followed by a recompression of the released gas (Baker et al. 1983 [3]). But when a pressure-liquefied gas vessel ruptures, flash vaporization occurs in addition to vapor expansion. A blast wave signal recorded after a large scale BLEVE experiment can be observed in Figure 1 (Johnson 1991 [4]). The physical explanation of the blast generation is still not clear. At first, it has been said that the first peak is linked to the vapor expansion and the second peak to the liquid flash vaporization. But then, Johnson proposed in his analysis that the first peak combines the liquid vaporization and the vapor expansion [4], as observed in Figure 1. And recently, Birk [5] suggested that the liquid flashing is too slow to produce a blast wave and that the overpressure is mostly driven by the vapor energy. If the BLEVE leads to a fireball, a third overpressure peak is generated by the combustion (see Figure 1). But the overpressure due to combustion is a mechanism that will not be considered in this study.

\section{BLEVE Overpressure Modeling}

In literature, blast wave modeling is dedicated to the prediction of the first peak amplitude, and the overpressure is modeled using generalized methods based on thermodynamic equations. The procedure first consists in the calculation of the expansion energy based on the change in thermodynamic state of the substance stored in the vessel from the initial state, which is the moment before the explosion to the final state where the fluid is at boiling temperature and atmospheric pressure. The expansion energy $(E)$ can be expressed differently depending on the model, but all the models are then using it in the calculation of a scaled distance $(\bar{R})$. This scaled distance can be expressed as the Sach's scaled distance, linked to the distance from the source and the atmospheric pressure, and defined in Eq. 1, or based on the TNT equivalent mass, as it will be explained later. 


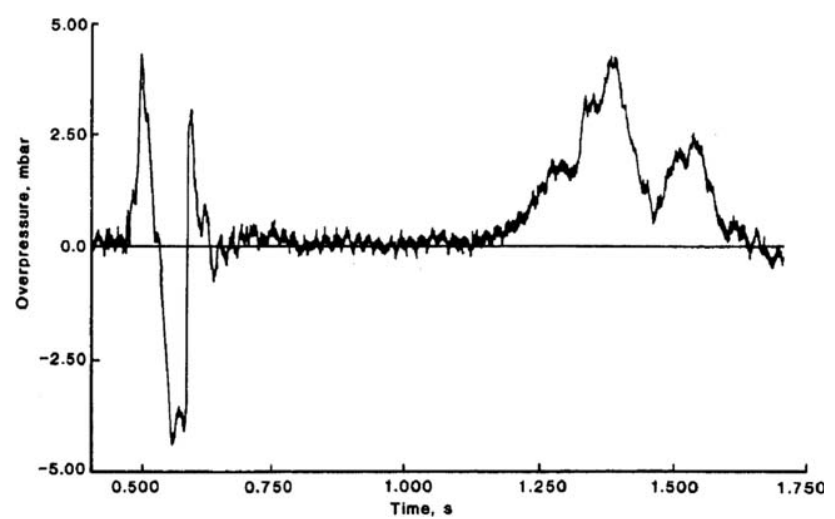

Figure 1. Pressure time history at $150 \mathrm{~m}$ from vessel (2 t propane vessel) [4].

$$
\bar{R}=r\left(\frac{P_{\mathrm{atm}}}{E}\right)^{1 / 3}
$$

The peak side-on overpressure can then be finally evaluated thanks to scaled overpressure curve (see Figure A2 $[1,6])$. Three models based on this procedure can be found in literature: the procedure from the Yellow book of TNO [6] and the models of Roberts [7] and Genova [8].

The TNO method [6] models separately the expansion energy of the liquid and vapor phases, each energy being defined as the product of the fluid phase mass with the difference in internal energies, assuming an isentropic expansion (see Eq. 2).

$$
E=m_{\mathrm{l}}\left(u_{11}-u_{12}\right)+m_{\mathrm{v}}\left(u_{\mathrm{v} 1}-u_{\mathrm{v} 2}\right)
$$

The total expansion energy is then multiplied by a factor two for ground effect and used in the calculation of the Sach's scaled distance. In near field, that is, close to the source, the blast wave generated after rupture of a pressurized vessel differs greatly from the detonation of high explosives, showing smaller overpressures [6]. Therefore, the TNO has developed a special procedure that consists in the calculation of the initial overpressure and the initial distance. The initial distance is modeled as the radius of a hemispherical vessel with a volume equivalent to the gas filled part of the actual vessel, assuming that the blast wave is completely symmetrical. The initial overpressure and radius are then compared to a set of curves (see Figure A3), and the closer curve is chosen to calculate the overpressure in near field (see Appendix for details).

In 1999, Roberts [7] improved the TNO method, keeping a definition of the expansion energy as the difference in internal energies of the liquid and vapor phases, but by considering that at the final state, a part of the liquid has flashed to vapor. Both phase fractions are calculated from ratios of entropy differences (see Appendix).

And finally, in 2008, Genova [8] proposed a new model for the expansion energy, assuming that this energy is mainly due to the liquid flash that can be seen as a thermal phenomenon, linked to the excess of heat stored inside the liquid. The expansion energy is then modeled as Eq. 3 where $\beta$ is an empirical coefficient, set to $7 \%$.

$$
E=\beta m_{\mathrm{l}} C_{\mathrm{p}}\left(T_{\text {rupt }}-T_{\mathrm{b}}\right)
$$

A similar procedure based on the TNT equivalent mass is also followed in other models, comparing the expansion energy with the energy released by $1 \mathrm{~kg}$ of TNT $(4,680 \mathrm{~kJ})$ and using TNT equivalent curves (see Figure A1 or [1]). Four authors developed a model based on the TNT equivalent: Prugh [9], Planas-Cuchi [10], Casal [11], and Birk [5].

In 1991, Prugh [9] first defined the expansion energy by assuming an isentropic expansion and an ideal gas behavior (see Eq. 4). The volume $V^{*}$ used in Eq. 4 is the sum of the vapor volume and the volume occupied by the flashed fraction of liquid.

$$
\begin{aligned}
& \left.m_{\mathrm{TNT}}=\left(\frac{0.021 P_{\mathrm{rupt}} V^{*}}{\gamma-1}\right) 1-\left(\frac{P_{\mathrm{atm}}}{P_{\mathrm{rupt}}}\right)^{(\gamma-1) / \gamma}\right) \\
& V^{*}=V_{\mathrm{v}}+V_{\mathrm{l}} f\left(\frac{\rho_{\mathrm{l}}}{\rho_{\mathrm{v}}}\right)
\end{aligned}
$$

In 2004, Planas-Cuchi [10] stated that an isentropic expansion as assumed by most of the previous models is an ideal case, thus overestimating the expansion energy. Planas-Cuchi proposed that the real expansion energy ranges between two values: the energy based on an isentropic expansion $(\Delta U)$ and the energy based on an adiabatic and irreversible expansion where the only work performed is the one associated with the variation of volume $(\Delta V)$.

$$
-P_{\mathrm{atm}} \Delta V=\Delta U
$$

The expansion energy is found by iteration on the final vapor fraction until the value satisfies Eq. 5. The expansion energy from both Prugh and Planas-Cuchi is then multiplied by a factor $\beta$, equal to $40 \%$ for ductile failure and $80 \%$ for brittle failure; the remaining energy being transformed into kinetic energy that propels the vessel fragments generated by the vessel rupture.

In 2006, Casal [11] introduced the liquid superheating energy (SE), defined as the difference between the enthalpy of the liquid prior rupture, and the enthalpy of the liquid at the saturation temperature corresponding the atmospheric pressure. The final TNT mass that contributes to the blast generation is supposed to be only a fraction: 5\% for an irreversible expansion and $14 \%$ for an isentropic one.

Finally, in 2007, after analysis of mid-scale experiments, Birk [5] concluded that the liquid part does not contribute to the blast wave generation. His new model is based on the TNO model but using only the vapor part to calculate the expansion energy (see Eq. 6). In addition, Birk uses a fit of the scaled overpressure curve to evaluate the overpressure (see Appendix).

$$
E=m_{\mathrm{v}}\left(u_{\mathrm{v} 1}-u_{\mathrm{v} 2}\right)
$$

\section{SUPERCRITICAL BLEVE}

To increase the experimental database of overpressure measurements available in literature, small scale experiments are performed within a von Karman testing program, in a dedicated facility called BABELs, which is an acronym for Bleve And Boilover ExperimentaL setup (Figure 2 left). It consists of a cylindrical chamber of $2 \mathrm{~m}$ diameter, and $3 \mathrm{~m}$ high, with round-shaped flanges, made out of steel with a rated pressure of 5 bar. It has three series of seven optical accesses of $0.15 \mathrm{~m}$ in diameter, separated by $90^{\circ}$ and a door of $0.57 \mathrm{~m} \times 0.77 \mathrm{~m}$. The setup allows air venting through 

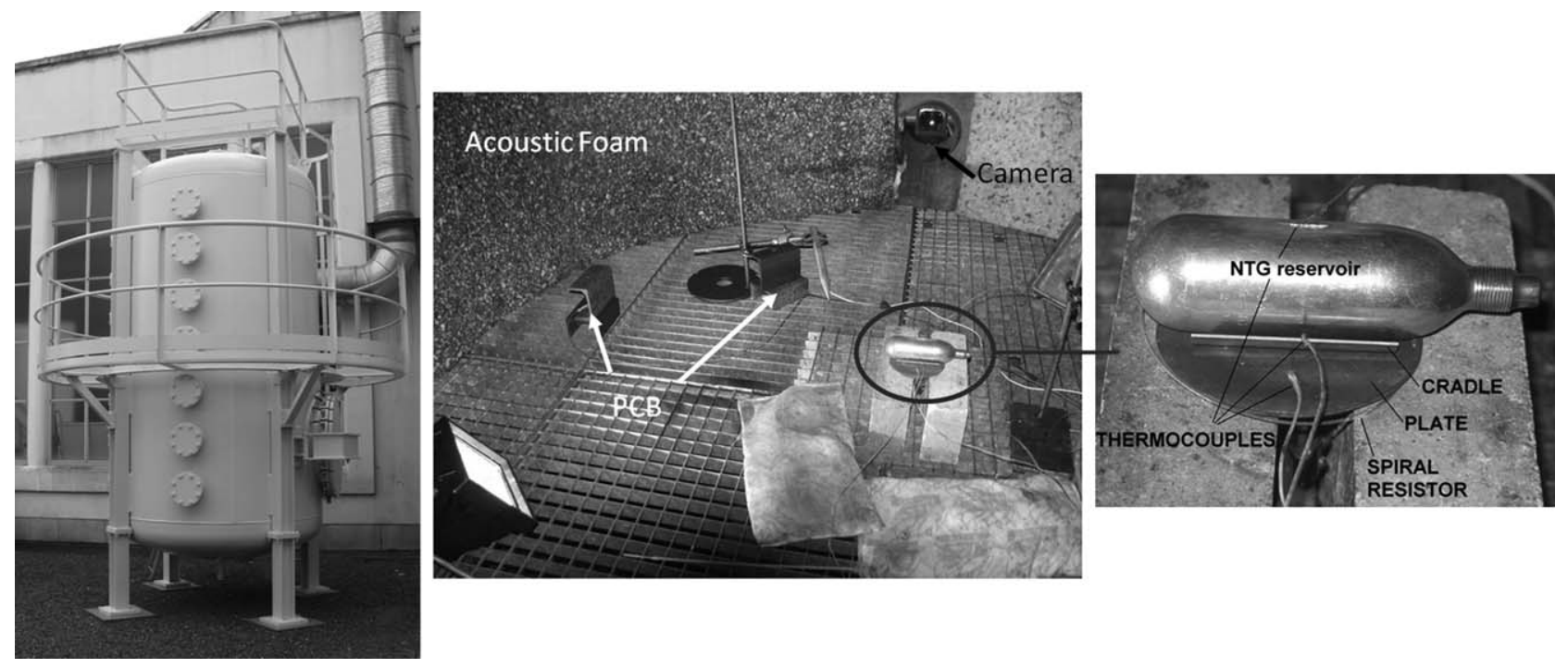

Figure 2. Left: BABELs facility, Right: NTG vessel and instrumentation.

openings in its bottom and upper parts. All the small scale experimental results of this testing program have been carried out in BABELs.

The BLEVE scenario of a vessel engulfed in fire is simulated at small scale using horizontal cylindrical vessels of 95 $\mathrm{ml}$ volume, filled at $86 \%$ with propane (mass: $0.041 \mathrm{~kg}$ ) provided by Nippon Tansan Gas Co (NTG), as shown in Figure 2 (right). This vessel is laid on a spiral microheater GA-XP from Micropyretics Heaters International. This resistor can be supplied with varying electrical power, changing the heat flux applied to the vessel by Joule effect. To protect the resistor from the vessel rupture, a metal plate is fitted atop the spiral microheater. The vessel is positioned on the plate inside a cradle for a better heat distribution and stability on the spiral microheater. As the vessel fragmentation during rupture is a phenomenon difficult to predict, the vessels are weakened prior the experiment. A scratch of $0.6 \mathrm{~mm}$ deep (approximately $20 \%$ of thickness removed) and $10 \mathrm{~mm}$ to 80 $\mathrm{mm}$ long is made along the length of the vessel and is located on top of it during the experiment.

Temperature is monitored by Type $\mathrm{K}$ thermocouples located between the plate and the cradle, at the top and the bottom of the vessel, and sampled at $3 \mathrm{~Hz}$. The pressure wave generated at rupture is recorded by two PCB 106B50 pressure transducers, filtered at $25 \mathrm{kHz}$ (to remove the influence of the $50 \mathrm{kHz}$ resonance frequency, determined by shock tube experiments) and sampled at $250 \mathrm{kHz}$. One of the vessels is also connected to a low cost pressure transducer from GE, model PMP1400 that monitors the internal pressure at $100 \mathrm{~Hz}$. All these measurements are recorded by National Instrument Compact DAQ and LabView acquisition software.

Figure 3 shows the internal pressure evolution of a BLEVE experiment performed with a weakness length of $40 \mathrm{~mm}$, plotted against the temperature of the top of the vessel. This measurement is compared with the experiment of Stawczyk performed in 2003 [12] that generated a BLEVE with a $5 \mathrm{~kg}$ vessel of propane, filled at $70 \%$. Both experiments follow the same trend. At first, the pressure is following the saturation line. Then, at one point below the critical point, the measurements deviate from the saturation line and show a linear increase in pressure. The fluid is then supercritical, since temperature and pressure are above their critical value, where distinct liquid and gas phases do not exist. As the fluid mass stays fixed and the fluid occupies the whole volume, the fluid density in supercritical state is constant and calculated as the fluid mass divided by the total volume of the vessel. This leads to a quasilinear pressure-temperature relationship, as observed in Figure 3 . The fundamental equation of state (EOS) applied to propane developed by Miyamoto and Watanabe [13] can reproduce the experiments with a good agreement.

In the literature review of the overpressure modeling presented in the previous section, all the authors have developed models for an overpressure generated after the rupture of a liquefied gas vessel at a pressure lower than the critical one, where the fluid follows the saturation line. But in these measurements, the fluid state prior to rupture is supercritical, leading to a supercritical BLEVE, which means that distinct liquid and gas phases do not exist anymore. Therefore, all the models using an expansion energy calculated from a combination of the liquid and vapor energies cannot be used with these rupture conditions.

The overpressure following the rupture of a vessel containing a supercritical fluid at rupture can be modeled by Birk, Genova, Prugh, and Casal [5,8,9,11]. For Prugh, the vapor volume is set equal to the volume of the vessel (as the

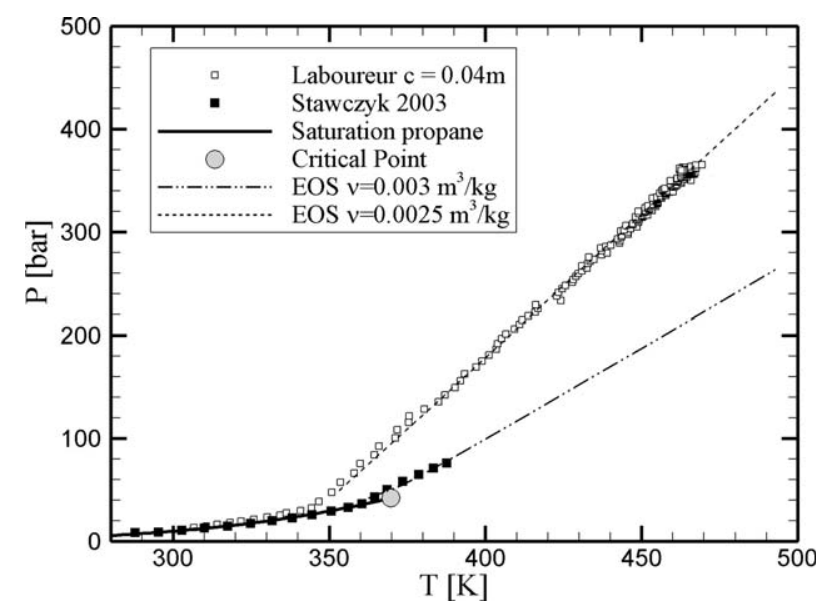

Figure 3. Vapor Pressure versus Temperature. 
Table 1. Estimation error of models compared with large scale experiments $[4,14]$.

\begin{tabular}{|c|c|c|c|c|c|c|c|c|}
\hline & Prugh & Casal IS & Casal IR & Planas & Roberts & Genova & TNO & Birk \\
\hline \multicolumn{9}{|c|}{ Johnson experiments } \\
\hline 1 & 0.60 & 0.91 & 0.23 & 0.17 & 0.71 & 0.03 & 0.71 & -0.26 \\
\hline 2 & 1.01 & 1.33 & 0.50 & 0.47 & 1.16 & 0.30 & 1.16 & -0.06 \\
\hline 3 & 0.88 & 1.06 & 0.35 & 0.37 & 0.99 & 0.14 & 0.99 & -0.34 \\
\hline 4 & 8.64 & 10.57 & 6.56 & 6.50 & 9.16 & 5.58 & 9.15 & 3.27 \\
\hline 5 & 0.92 & 1.01 & 0.31 & 0.41 & 1.02 & 0.15 & 1.02 & 0.45 \\
\hline 6 & 3.73 & 2.72 & 1.40 & 2.38 & 3.97 & 1.99 & 3.81 & 1.13 \\
\hline 7 & 0.65 & 0.95 & 0.26 & 0.19 & 0.71 & 0.02 & 0.70 & -0.27 \\
\hline All & 2.45 & 2.75 & 1.44 & 1.58 & 2.64 & 1.24 & 2.62 & 0.61 \\
\hline \multicolumn{9}{|c|}{ BAM experiments } \\
\hline 1 & 0.58 & 0.1 & -0.29 & 0.11 & 0.69 & -0.23 & 0.72 & 0.7 \\
\hline
\end{tabular}

Table 2. Large scale measurements data [4,14].

\begin{tabular}{|c|c|c|c|c|c|c|}
\hline & Fluid & $m(\mathrm{~kg})$ & $V\left(\mathrm{~m}^{3}\right)$ & $P_{\text {rupt }}$ (bar) & $R(\mathrm{~m})$ & $P_{\mathrm{s}}(\mathrm{mbar})$ \\
\hline \multicolumn{7}{|c|}{ Johnson experiments } \\
\hline 1 & Butane & 2,000 & 5.659 & 14.6 & $25 / 100 / 150$ & $62 / 13 / 11$ \\
\hline 2 & Butane & 2,000 & 5.659 & 15.1 & $25 / 50 / 100 / 150 /$ & 63/39/9/6/ \\
\hline 3 & Butane & 1,000 & 5.659 & 15.2 & $25 / 50 / 100 / 150 /$ & $50 / 28 / 12 / 8 /$ \\
\hline 4 & Butane & 2,000 & 5.659 & 7.7 & 25/50/100/150/ & $10 / 5 / 1.7 / 1.5 /$ \\
\hline 5 & Butane & 2,000 & 10.796 & 15.1 & $25 / 50 / 100 / 150 /$ & $82 / 34 / 14 / 7 /$ \\
\hline 6 & Propane & 2,000 & 5.659 & 15.2 & 25/50/100/150/ & 23/12/3/3/ \\
\hline 7 & Butane & 2,000 & 5.659 & 15.2 & $25 / 50 / 100 /$ & 70/34/13/ \\
\hline \multicolumn{7}{|c|}{ BAM experiments } \\
\hline 1 & Propane & 3367 & 45.36 & 25 & $100 / 150 / 200$ & $25 / 14 / 12$ \\
\hline
\end{tabular}

fluid occupies the whole vessel in supercritical conditions). Birk, Genova, and Casal models can be used directly but by using the total fluid mass instead of only using the liquid mass or vapor mass. The thermophysical properties needed in these different models are determined based on the rupture pressure at constant density, as showed in Figure 3.

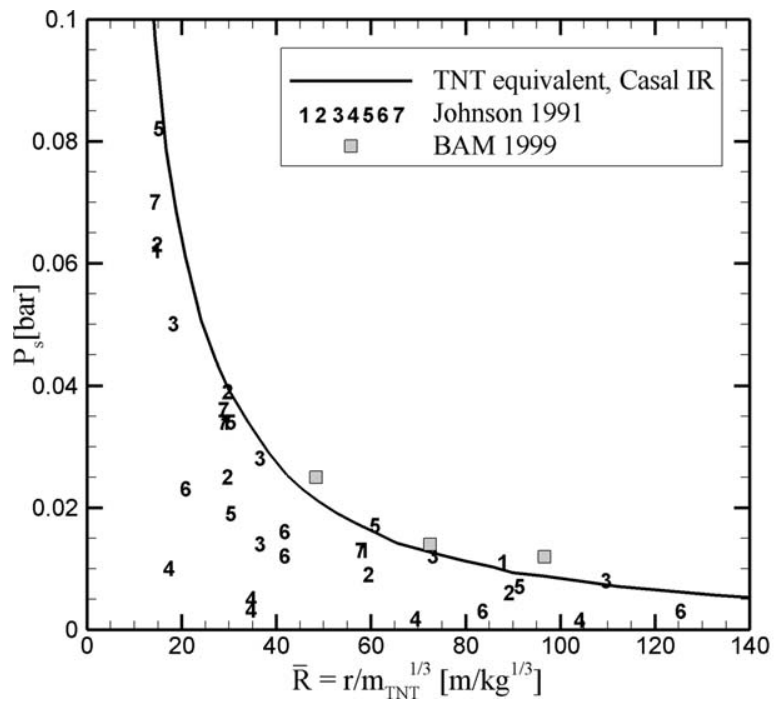

\section{COMPARISON OF OVERPRESSURE MODELS}

To compare the available models, different scales of experiments are needed. Small scale is defined here as a size of bottle that can be found in residential homes, with a maximal weight of several tens of kilograms. Large scale is similar to industrial containers, so with a fluid mass higher than a ton. And finally, mid-scale is lying in between. The difference

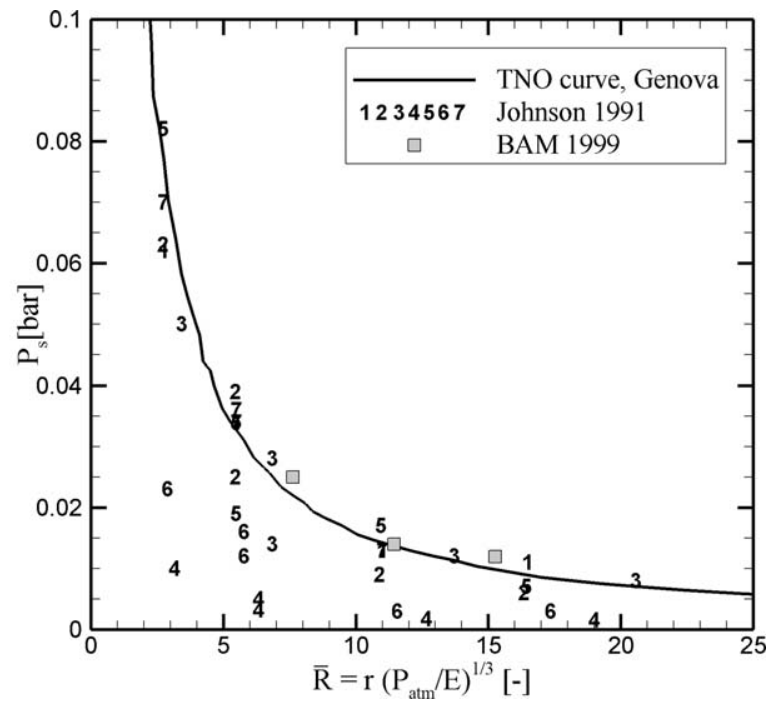

Figure 4. Comparison of large scale experiments of Johnson 1991 and BAM 1999 with Casal IR model (left) and Genova model (right). 
Table 3. Estimation error of models compared with mid-scale experiments [5].

\begin{tabular}{|c|c|c|c|c|c|c|c|c|}
\hline & Prugh & Casal IS & Casal IR & Planas & Roberts & Genova & TNO & Birk \\
\hline \multicolumn{9}{|c|}{ Birk experiments } \\
\hline 1 & 0.77 & 0.14 & -0.26 & 0.22 & 0.87 & -0.19 & 0.84 & 0.76 \\
\hline 2 & 1.97 & 1.20 & 0.40 & 1.03 & 2.17 & 0.54 & 2.12 & 1.23 \\
\hline 3 & 1.41 & 0.44 & -0.07 & 0.66 & 1.53 & 0.05 & 1.46 & 1.49 \\
\hline 4 & 1.97 & 0.95 & 0.22 & 0.98 & 2.19 & 0.33 & 2.13 & 1.77 \\
\hline 5 & 1.75 & 0.60 & 0.03 & 0.91 & 1.80 & 0.21 & 1.71 & 1.86 \\
\hline 6 & 0.23 & -0.03 & -0.39 & -0.16 & 0.28 & -0.32 & 0.24 & -0.27 \\
\hline 7 & 2.22 & 1.56 & 0.62 & 1.28 & 2.39 & 0.91 & 2.31 & 0.94 \\
\hline 8 & 2.09 & 1.57 & 0.61 & 1.16 & 2.32 & 0.80 & 2.22 & 0.93 \\
\hline 9 & 1.45 & 1.10 & 0.31 & 0.73 & 1.70 & 0.44 & 1.64 & 0.41 \\
\hline All & 1.52 & 0.84 & 0.17 & 0.74 & 1.67 & 0.31 & 1.60 & 0.95 \\
\hline
\end{tabular}

Table 4. Mid-scale experimental data [5].

\begin{tabular}{lllllll}
\hline & Fluid & $m(\mathrm{~kg})$ & $V\left(\mathrm{~m}^{3}\right)$ & $P_{\text {rupt }}(\mathrm{bar})$ & \multicolumn{1}{c}{$R(\mathrm{~m})$} & $P_{\mathrm{s}}(\mathrm{mbar})$ \\
\hline Birk experiments & & & & & \\
1 & Propane & 150 & 2 & 18.63 & $10 / 20 / 30 \mathrm{e} / 30 \mathrm{~s} / 40 \mathrm{e} / 40 \mathrm{~s}$ & $66.5 / 35 / 31.1 / 41.9 / 21.1 / 27.3$ \\
2 & Propane & 309.4 & 2 & 18.46 & $10 / 20 / 30 / 40 \mathrm{e} / 40 \mathrm{~s}$ & $39.7 / 37.8 / 22.9 / 14.8 / 21.3$ \\
3 & Propane & 116.9 & 2 & 16.99 & $10 / 20 / 40 \mathrm{e} / 40 \mathrm{~s}$ & $52.9 / 27.5 / 17.2 / 18.3$ \\
4 & Propane & 184.6 & 2 & 18.94 & $10 / 40$ & $50.2 / 16.75$ \\
5 & Propane & 109.5 & 2 & 15.73 & $10 / 20 / 30 / 40$ & $41.3 / 25.8 / 15.8 / 13.1$ \\
6 & Propane & 453.1 & 2 & 18.03 & $10 / 20 / 30 \mathrm{e} / 30 \mathrm{~s} / 40 \mathrm{e} / 40 \mathrm{~s}$ & $131.1 / 89.5 / 60.3 / 29.9 / 33.7 / 40.6$ \\
7 & Propane & 475.2 & 2 & 15.63 & $10 / 20 / 30 / 40$ & $45.63 / 34 / 19.3 / 15.8$ \\
8 & Propane & 470.3 & 2 & 18.13 & $10 / 20 / 30 \mathrm{e} / 30 \mathrm{~s} / 40 \mathrm{e} / 40 \mathrm{~s}$ & $41.5 / 29.9 / 29.9 / 22.9 / 26 / 6.4$ \\
9 & Propane & 538.5 & 2 & 18.58 & $10 / 20 / 30 / 40$ & $54.4 / 50.5 / 35.9 / 27$ \\
\hline
\end{tabular}

scales can also be expressed in terms of TNT equivalent mass; $m_{\mathrm{TNT}}>1$ for large scales, $m_{\mathrm{TNT}} \cong 1$ for mid-scales and $m_{\text {TNT }}<1$ for small scales. In the following section, each scale will be compared with the overpressure models coming from the literature, resumed in the previous section.

\section{Large Scale Experiments}

In 1991, seven BLEVE experiments were performed by British gas in the frame of a European commission research project and published by Johnson [4]. The reference case

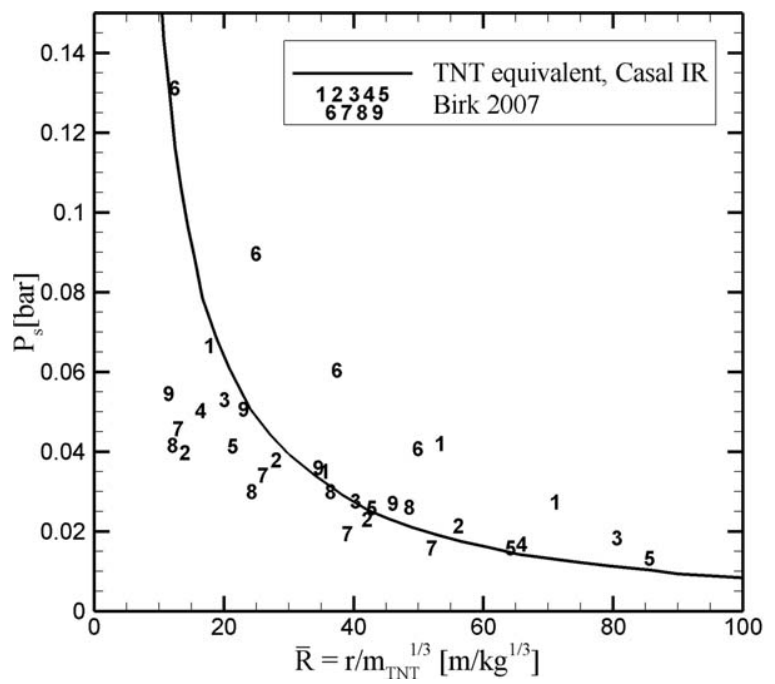

was a $5.6 \mathrm{~m}^{3}$ vessel, containing 2 tons of butane that was heated until a pressure of 15 bar, and then ruptured by detonation of a linear shape explosive. A parametric analysis of the fluid mass (changed to 1 ton) or type (changed to propane), of the vessel volume (doubled), and of the rupture pressure (halved) was performed. The overpressure was measured at 25, 50, 75, 100, and $150 \mathrm{~m}$ from the source, in different directions. An example of overpressure signal measured during these experiments has been presented in Figure 1. A few years later, the federal institute of material

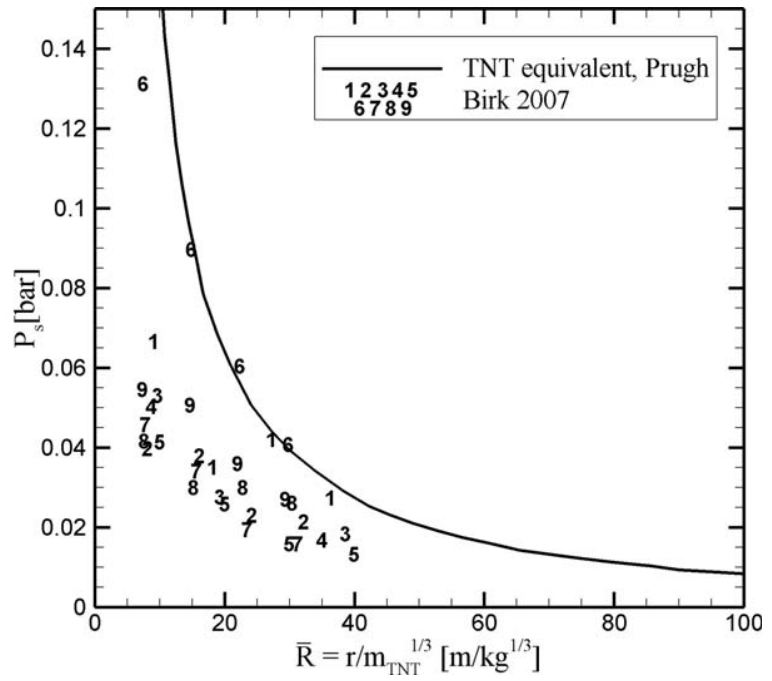

Figure 5. Comparison of Casal model, irreversible expansion (left) and Prugh (right) with Birk experiments [5]. 

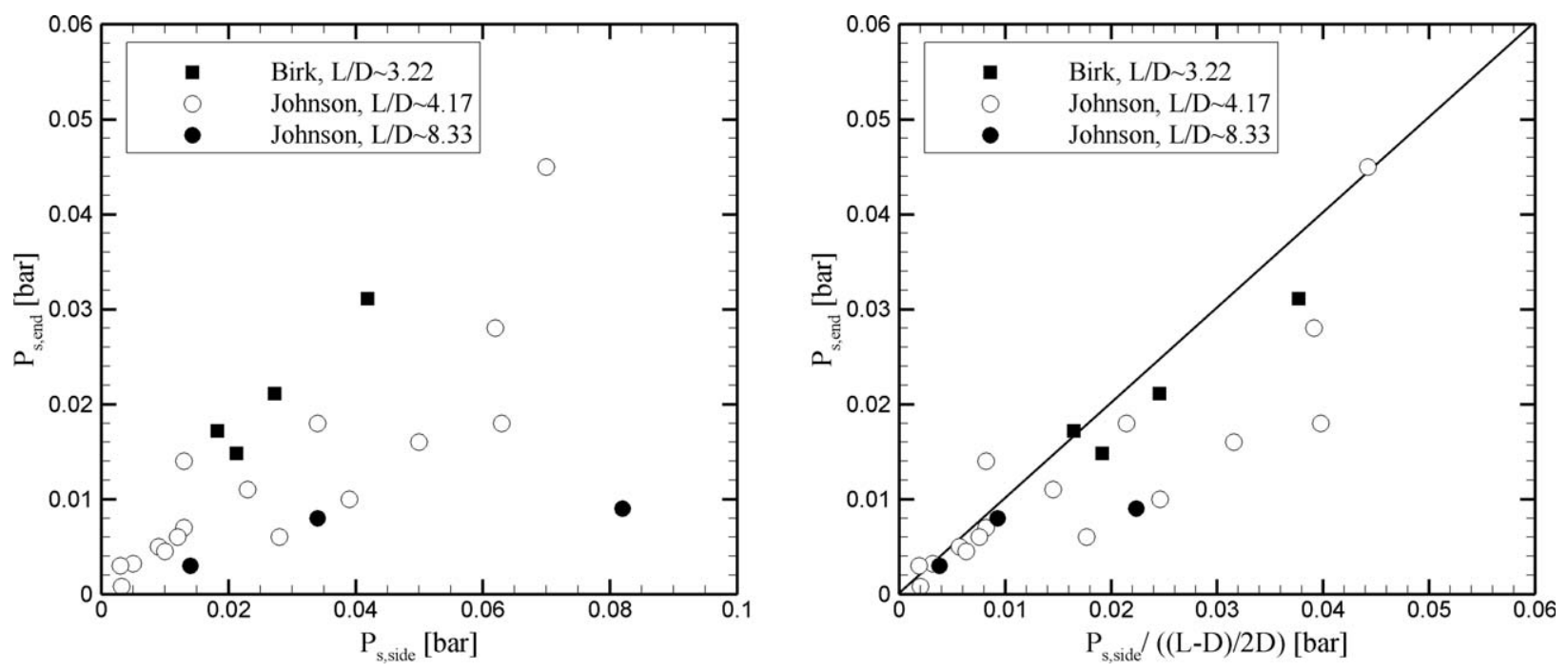

Figure 6. Relationship between the overpressure measured at the tank sides and ends.

research and testing (BAM) in Germany performed a BLEVE test with a $45 \mathrm{~m}^{3}$ vessel, filled at $22 \%$ ( 5 tons) with propane [14]. It ruptured at 25 bar after being immersed in a hydrocarbon pool fire. The blast wave was recorded at 100, 150, and $200 \mathrm{~m}$ from the source.

Table 1 lists the errors, evaluated between the different model predictions and the measured overpressures at the tank side, described in Table 2 . The error is calculated as the difference between the model prediction and the measurement value, divided by the measurement value. Each error value is an average of the different overpressures measured in one test. The general error for all the tests of Johnson is also presented.

For the tests made by Johnson, the models of Casal with irreversible expansion, Genova and Birk show the best estimation with the data. For the BAM experiment, the prediction of Birk is not as good as Genova and Casal. Looking at the measurements scaled with the models of Casal and Genova (see Figure 4), these models show a very slight underestimation for a few tests that can be considered as acceptable. But if a fully conservative approach is preferred, the best model is Prugh.

\section{Mid-Scale Experiments}

In 2007, Birk published a series of BLEVE experiments that were performed between 2001 and 2002 with $1.9 \mathrm{~m}^{3}$ ASME code propane tanks. Internal pressure, temperatures at different positions inside the vessel and overpressures at 10 $\mathrm{m}$ to $40 \mathrm{~m}$ both at side and end directions from the vessel have been measured. Among the series of tests conducted, nine of them resulted in a BLEVE, with a failure pressure between 15 bar and 20 bar. During heating of the vessel, the pressure relief valve connected to the vessel opened before the vessel rupture, once the internal pressure has exceeded the vessel design pressure. Therefore, a certain quantity of propane was ejected prior to rupture, decreasing the percentage of the fluid remaining inside the vessel to 15-60\%, depending on the test. In the article [5], the author gives the conditions at rupture and the corresponding overpressures at different distances and directions.

Table 3 presents for each test and each model, the error evaluated between the different peak overpressures, measured at $10-40 \mathrm{~m}$ from the tank side and described in Table 4 and the modeled overpressures. In addition, the error of the whole test results is also presented for each model.

From Table 3, Casal assuming an irreversible expansion and Genova are the best models, considering that each model is associated with an uncertainty. But the possible underestimation of Casal is more pronounced in this scale, as shown in Figure 5 left, where all measured points of a test are represented by their corresponding test number. Among the conservative models (Prugh, TNO, Roberts), Prugh is the one that gives the best agreement with the measurements (see Figure 5). In both graphs of Figure 5, the distance at which the overpressures have been measured is scaled with the TNT mass calculated respectively from Casal and Prugh model.

\section{Blast Wave Directivity}

The overpressure, for the large and mid-scale experiments, has been measured at different directions from the vessel, at equal distance from the vessel. Both Birk and Johnson showed that the overpressure along the side of the vessel (perpendicular to the vessel longitudinal axis) is higher

Table 5. Estimation error of models compared with small scale experiments.

\begin{tabular}{|c|c|c|c|c|c|}
\hline & Prugh & Casal IS & Casal IR & Genova & Birk \\
\hline \multicolumn{6}{|c|}{ BABELs experiments } \\
\hline 1 & 0.56 & -0.12 & -0.48 & -0.57 & 0.55 \\
\hline 2 & 1.50 & 0.40 & -0.16 & -0.24 & 1.52 \\
\hline 3 & 3.72 & 1.79 & 0.69 & 0.65 & 4.09 \\
\hline 4 & 2.74 & 1.08 & 0.24 & 0.10 & 2.75 \\
\hline 5 & 2.91 & 1.15 & 0.28 & 0.12 & 2.90 \\
\hline 6 & 1.05 & 0.11 & -0.34 & -0.44 & 1.02 \\
\hline 7 & 1.43 & 0.25 & -0.26 & 0.37 & 1.32 \\
\hline 8 & 2.81 & 1.19 & 0.31 & 0.16 & 2.86 \\
\hline 9 & 0.73 & -0.03 & -0.43 & -0.52 & 0.72 \\
\hline 10 & 2.85 & 1.28 & 0.36 & 0.23 & 3.00 \\
\hline 11 & 4.01 & 1.94 & 0.75 & 0.53 & 4.20 \\
\hline All & 2.22 & 0.82 & 0.09 & -0.03 & 2.27 \\
\hline \multicolumn{6}{|c|}{ Stawczyk experiments } \\
\hline 1 & -0.0002 & 0.026 & -0.39 & -0.41 & 0.93 \\
\hline
\end{tabular}



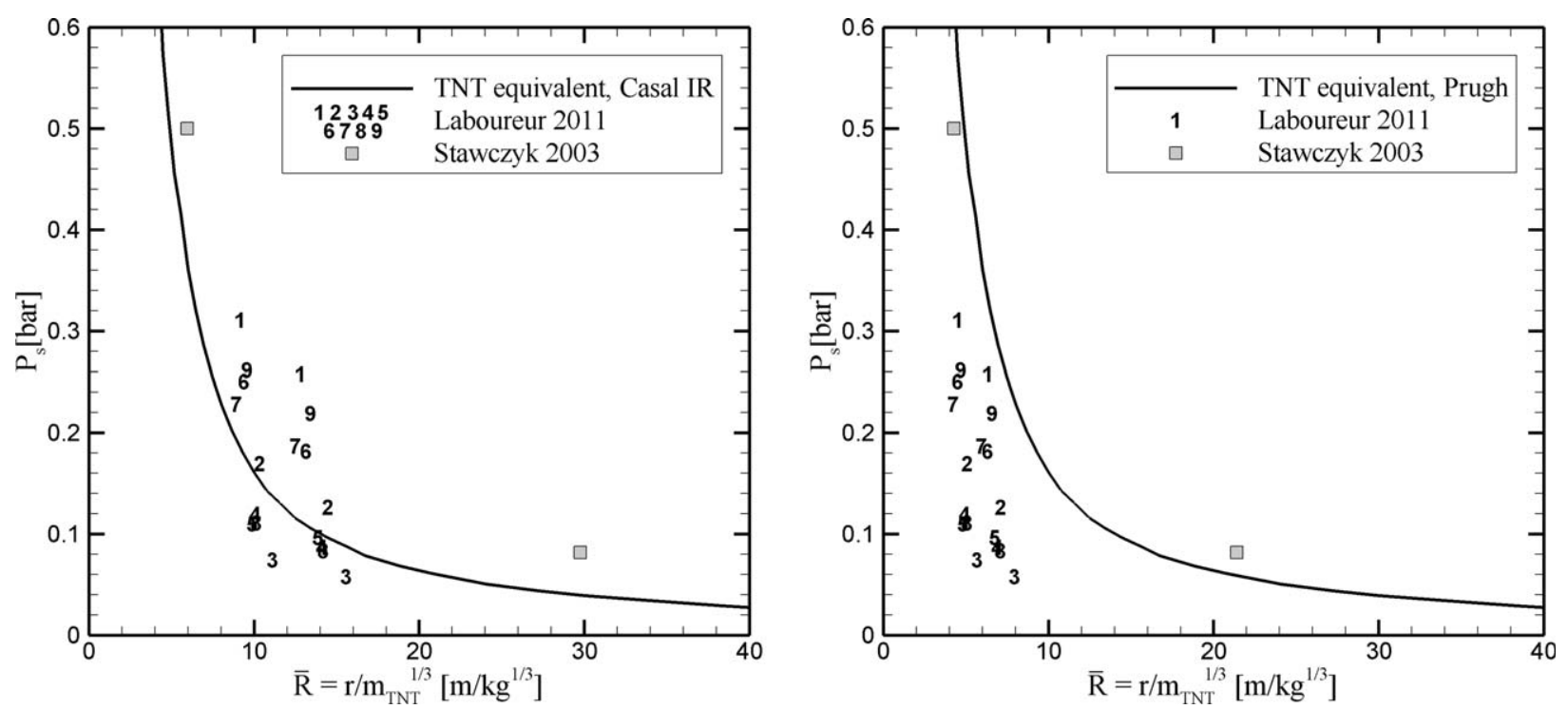

Figure 7. Comparison small scale experiments with Casal model (left) with irreversible expansion and Prugh model (right).

than the overpressure along the end of the vessel (along the vessel longitudinal axis). Therefore, for a conservative approach, the overpressure measurements at the side have been used in the comparison with the overpressure models.

From the experiments, when the shape of a vessel gets away from the spherical shape, that is, the ratio between the vessel length and diameter increases, the directivity of the overpressure increases, as illustrated in Figure 6 left. The vessel geometry can be used to predict the end overpressure, by dividing the side overpressure by the ratio between half the vessel length and diameter difference ([L-D]/2) and the vessel diameter, as observed in Figure 6 right.

\section{Small Scale Experiments}

The small scale vessels are usually dedicated to a domestic use, and therefore, are usually resistant to higher pressures than the large scale vessels, which causes the BLEVE to happen when the fluid is supercritical. In 2003, Stawczyk tested supercritical BLEVE on 5 and $11 \mathrm{~kg}$ commercial propane vessels. The author has presented two blast wave signals recorded at 2 and $10 \mathrm{~m}$ from the source, with $11 \mathrm{~kg}$ bottle filled at $80 \%$ [12]. In parallel, the measurements performed by the authors are also presented. As described before, supercritical BLEVE can only be modeled by Prugh, Casal, Birk, and Genova.

Table 5 and Figure 7 compare the discrepancy between models and experiments from Stawczyk [12] and also from the experiments performed in the frame of this study, described in Table 6. For the tests of this study, the global error is also presented. Similar to Figure 5, the experiments of Figure 7 are scaled with the TNT mass calculated from the Casal and Prugh models, respectively.

Concerning the small scale experiments performed in this study, even if the fluid state prior to rupture differs from the other scales of experiments, the models of Casal with an irreversible expansion and Genova show the best agreement with data. But they also underestimate a part of the measurements. Among the conservative approaches, Prugh does not underestimate any tests, as observed in Figure 7.

Table 6. Small scale experimental data.

\begin{tabular}{|c|c|c|c|c|c|c|}
\hline & Fluid & $m(\mathrm{~kg})$ & $V\left(\mathrm{~m}^{3}\right)$ & $P_{\text {rupt }}$ (bar) & $R(\mathrm{~m})$ & $P_{\mathrm{s}}$ (mbar) \\
\hline \multicolumn{7}{|c|}{ BABELs experiments } \\
\hline 1 & Propane & 0.041 & $9.5 \times 10^{-5}$ & 394.000 & $0.5 / 0.7$ & $310.3 / 257.2$ \\
\hline 2 & Propane & 0.041 & $9.5 \times 10^{-5}$ & 281.350 & $0.5 / 0.7$ & $168.9 / 126.2$ \\
\hline 3 & Propane & 0.041 & $9.5 \times 10^{-5}$ & 209.906 & $0.5 / 0.7$ & $73.8 / 57.5$ \\
\hline 4 & Propane & 0.041 & $9.5 \times 10^{-5}$ & 305.391 & $0.5 / 0.7$ & $118.9 / 86.6$ \\
\hline 5 & Propane & 0.041 & $9.5 \times 10^{-5}$ & 325.368 & $0.5 / 0.7$ & $109.4 / 95.9$ \\
\hline 6 & Propane & 0.041 & $9.5 \times 10^{-5}$ & 391.734 & $0.5 / 0.7$ & $249.9 / 181.3$ \\
\hline 7 & Propane & 0.041 & $9.5 \times 10^{-5}$ & 461.486 & $0.5 / 0.7$ & $227.6 / 186.4$ \\
\hline 8 & Propane & 0.041 & $9.5 \times 10^{-5}$ & 284.736 & $0.5 / 0.7$ & $110.4 / 83.1$ \\
\hline 9 & Propane & 0.041 & $9.5 \times 10^{-5}$ & 348.732 & $0.5 / 0.7$ & $261.1 / 218.7$ \\
\hline 10 & Propane & 0.041 & $9.5 \times 10^{-5}$ & 251.554 & $0.5 / 0.7$ & $92.2 / 89.3$ \\
\hline 11 & Propane & 0.041 & $9.5 \times 10^{-5}$ & 298.619 & $0.5 / 0.7$ & $76.5 / 72.95$ \\
\hline \multicolumn{7}{|c|}{ Stawczyk experiments } \\
\hline 1 & Propane & 10.88 & 0.027 & 80 & $2 / 10$ & $500 / 81.9$ \\
\hline
\end{tabular}



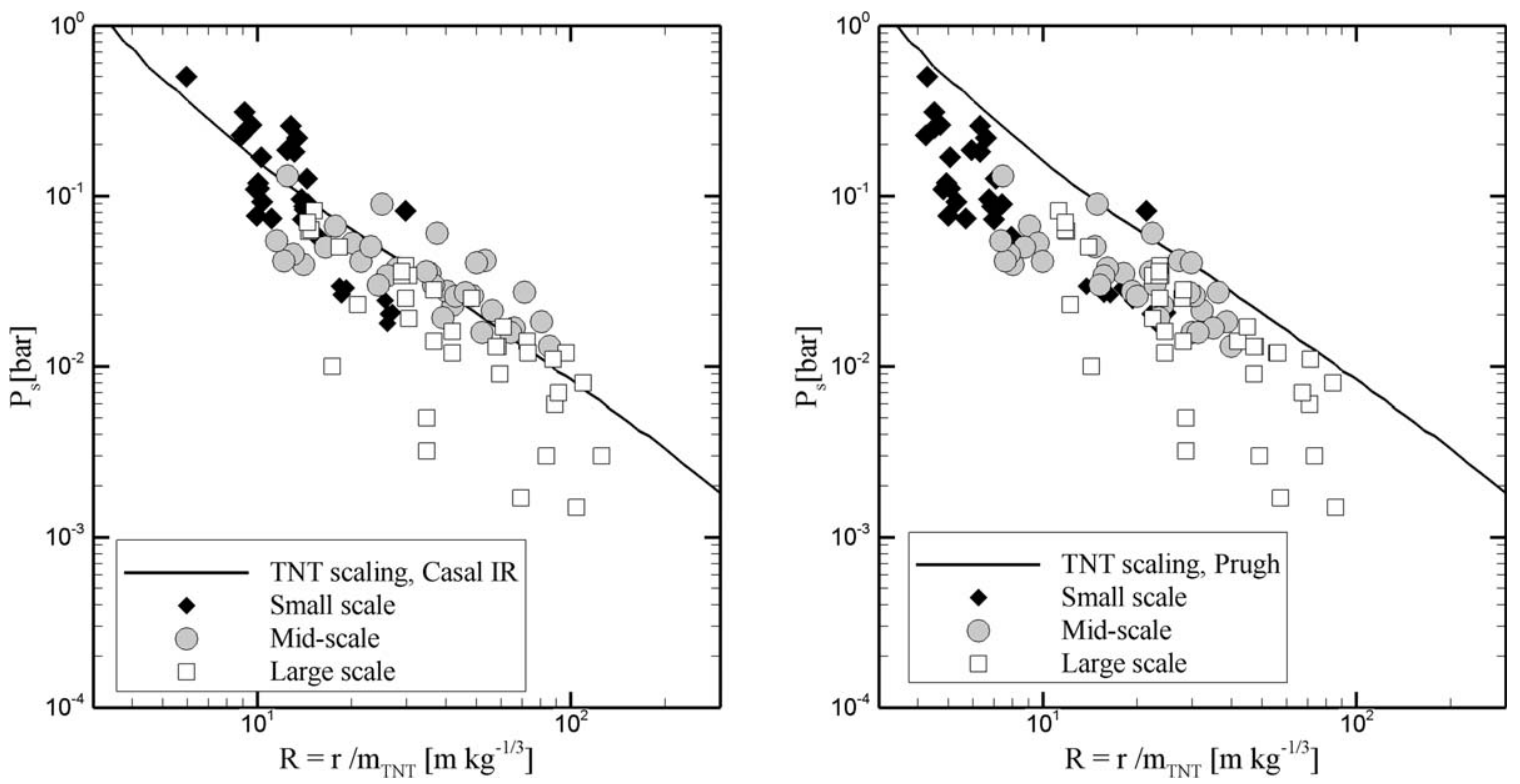

Figure 8. Casal model with irreversible expansion (left) and Prugh model (right) compared with all scales experimental data.

Concerning the measurements of Stawczyk, the models that are best at estimating the measured overpressure are Prugh and Casal with an isentropic expansion. This conclusion differs greatly from the previous comparison but has to be taken with care. Actually, the two measurement points of Stawczyk are related to two different experiments that could have different rupture pressures, which is not clearly stated in the publication; only the range of rupture pressures (75120 bar) is given.

\section{CONCLUSION}

This article presents a multiscale comparison between the different methods to evaluate the overpressure generated by a BLEVE published in literature with experiments. The models of Prugh, TNO, Roberts, Casal, Planas-Cuchi, Birk, and Genova are compared with large scale experiments of Johnson and BAM, mid-scale experiments of Birk and small scale experiments of Stawczyk and results of an experimental campaign performed with $95 \mathrm{ml}$ propane vessels in the BABELs facility from present authors.

From the different scales, Genova and Casal with an irreversible expansion are the two models that are fitting the best the measured overpressure, whatever the scale of the vessel or the fluid state prior rupture, as observed in Figure 8 left. But the models of Genova and Casal IR are for some experiments underestimating the predicted overpressure. Therefore, the model that fits the best the experiments in a conservative approach is Prugh (see Figure 8). The side peak overpressure is modeled through the overpressure models, and the end overpressure is directly calculated from the side value and from the geometrical parameters of the vessel.

But the models of Casal and Genova, which give the best estimation in terms of error, are both relying on a fitting parameter. In addition, the measurement results in all scales show a large discrepancy, which is not yet clearly understood. Therefore, more research is needed to better understand the physics behind the blast waves generated by a BLEVE, and on to develop a model more closely related to the physical phenomenon.

\author{
NOMENCLATURE \\ a Sound velocity $(\mathrm{m} / \mathrm{s})$ \\ $C_{\mathrm{p}} \quad$ Specific heat $(\mathrm{kJ} / \mathrm{kgK})$ \\ $D \quad$ Vessel diameter $(\mathrm{m})$ \\ E Expansion energy (kJ) \\ $f \quad$ Flash fraction \\ $b$ Enthalpy $(\mathrm{kJ} / \mathrm{kg})$ \\ $H_{\mathrm{v}} \quad$ Enthalpy of vaporization $(\mathrm{kJ} / \mathrm{kg})$ \\ $L \quad$ Vessel length (m) \\ $m$ Mass $(\mathrm{kg})$ \\ $P \quad$ Pressure (bar) \\ $r \quad$ Distance from source $(\mathrm{m})$ \\ $R \quad$ Scaled distance \\ $s \quad$ Entropy $(\mathrm{kJ} / \mathrm{kg})$ \\ SE Superheating energy $(\mathrm{kJ} / \mathrm{kg})$ \\ $T$ Temperature (K) \\ $u$ Internal energy $(\mathrm{kJ} / \mathrm{kg})$ \\ $U \quad$ Internal energy (kJ) \\ $V \quad$ Volume $\left(\mathrm{m}^{3}\right)$ \\ $X \quad$ Vapor fraction
}

\section{Greek letters}

$\beta$ Coefficient

$\gamma$ Specific heat ratio of vapor

$\mu$ Molar mass $(\mathrm{kg} / \mathrm{mol})$

$\rho$ Density $\left(\mathrm{kg} / \mathrm{m}^{3}\right)$

\section{Subscripts}

Atm Ambient

1 Prior rupture

2 After rupture

a Air

b Boiling

c Critical

end Vessel end

1 Liquid 
rupt Rupture

s Overpressure

s0 Initial

side Vessel side

tot Total

TNT TNT equivalent

v Vapor

\section{APPENDIX: OVERPRESSURE MODELS DETAILS}

\section{Model of Prugh (1991) [9]}

$$
\begin{aligned}
& H_{\mathrm{V}}=h_{\mathrm{v}}\left(T_{\mathrm{b}}\right)-h_{\mathrm{l}}\left(T_{\mathrm{b}}\right)
\end{aligned}
$$

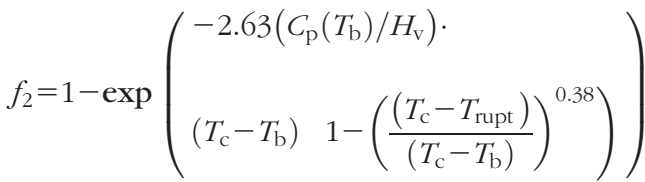

$$
\begin{aligned}
& V^{*}= \begin{cases}V_{\mathrm{v}}+V_{\mathrm{l}} f_{2}\left(\frac{\rho_{\mathrm{l}}}{\rho_{\mathrm{v}}}\right) & \text { if } P_{\text {rupt }}<P_{\mathrm{c}} \\
V & \text { if } P_{\text {rupt }}>P_{\mathrm{C}}\end{cases} \\
& \left.m_{\mathrm{TNT}-\text { Prugh }}=\left(\frac{2.4 e^{-2} P_{\mathrm{rupt}} V^{*}}{\gamma-1}\right) 1-\left(\frac{P_{\mathrm{atm}}}{P_{\text {rupt }}}\right)^{(\gamma-1) / \gamma}\right) \\
& \bar{R}_{\operatorname{Pr} u g h}=\frac{r}{\left(0.4 m_{T N T-P r u g h}\right)^{1 / 3}}
\end{aligned}
$$

Find the overpressure by using $\bar{R}_{\text {Prugh }}$ in Figure A1.

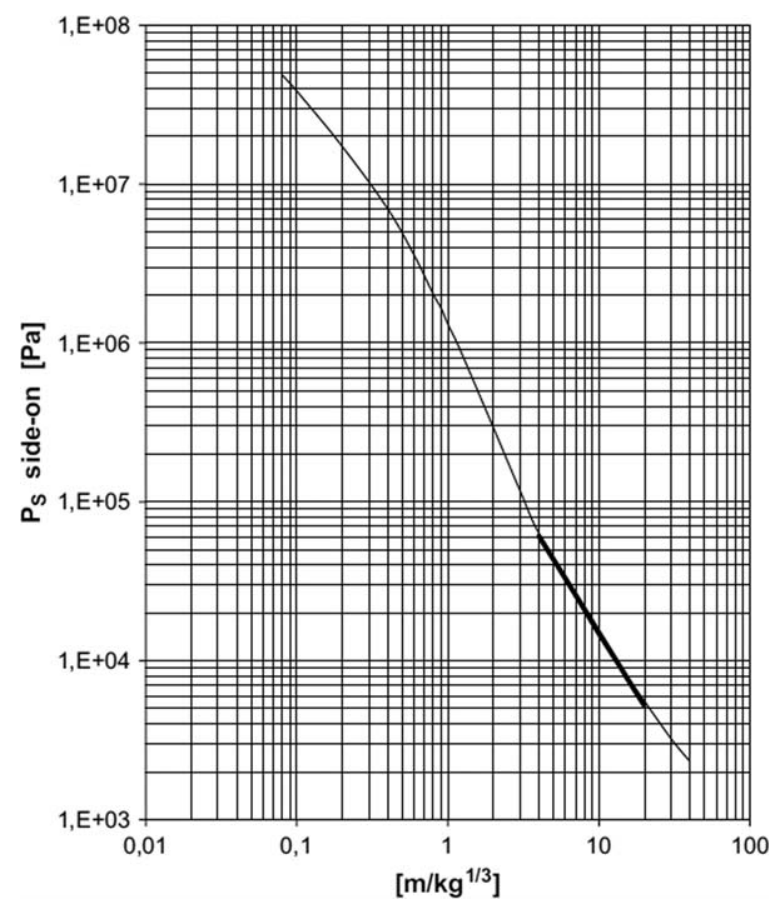

Figure A 1. TNT equivalent overpressure curve [15].
Model of Planas-Cuchi (2004) [10]

$$
\begin{aligned}
& U_{1}=m_{\mathrm{v}} u_{1 \mathrm{v}}+m_{l} u_{11} \\
& V_{1}=V
\end{aligned}
$$

Iterative procedure to find $x_{2}$, such that

$$
\begin{gathered}
U_{2}=x_{2} m_{\mathrm{tot}} u_{2 \mathrm{v}}+\left(1-x_{2}\right) m_{\mathrm{tot}} u_{2 \mathrm{l}} \\
V_{2}=\frac{x_{2} m_{\mathrm{tot}}}{\rho_{v}\left(P_{\mathrm{atm}}\right)}+\left(1-x_{2}\right) \frac{m_{\mathrm{tot}}}{\rho_{l}\left(P_{\mathrm{atm}}\right)} \\
\Delta U=U_{2}-U_{1} \\
\Delta V=V_{2}-V_{1}
\end{gathered}
$$

And: $-0.1 P_{\mathrm{atm}} \Delta V=10^{-3} \Delta U$ (Factors to fit units of $M P a$. $m^{3}$ or $\left.M J\right)$

Once $x_{2}$ is found: $m_{\text {TNT-Planas }}=0.214 * \Delta U$

$$
\bar{R}_{\text {Planas }}=\frac{r}{\left(0.4 m_{\text {TNT-Planas }}\right)^{1 / 3}}
$$

Find the overpressure by using $\bar{R}_{\text {Planas }}$ in Figure A1.

\section{Model of Casal with Isentropic Expansion (2006) [11]}

$$
\mathrm{SE}=h\left(P_{\text {rupt }}\right)-b\left(T_{\text {atm }}\right)
$$

If $P_{\text {rupt }}<P_{\mathrm{c}}$

$$
\begin{aligned}
m_{\text {TNT-casalIS }} & =0.214 e^{-3} 0.14 m_{1} \mathrm{SE} \\
\bar{R}_{\text {casalIs }} & =\frac{r}{\left(m_{\text {TNT-casalIS }}\right)^{1 / 3}}
\end{aligned}
$$

If $P_{\text {rupt }}>P_{\mathrm{C}}$

$$
\begin{aligned}
& m_{\mathrm{TNT} \text {-casalIS }}=0.214 e^{-3} 0.14 m_{\mathrm{tot}} S E \\
& \bar{R}_{\text {casalIS }}=\frac{r}{\left(m_{\mathrm{TNT} \text {-casalIS }}\right)^{1 / 3}}
\end{aligned}
$$

Find the overpressure by using $\bar{R}_{\text {casalIs }}$ in Figure A1.

\section{Model of Casal with Irreversible Expansion (2006) [11]}

$$
\mathrm{SE}=b\left(P_{\text {rupt }}\right)-b\left(T_{\text {atm }}\right)
$$

If $P_{\text {rupt }}<P_{\mathrm{c}}$

$$
\begin{aligned}
m_{\mathrm{TNT}-\text { casalIR }} & =0.214 e^{-3} 0.05 m_{\mathrm{l}} \mathrm{SE} \\
\bar{R}_{\text {casalIR }} & =\frac{r}{\left(m_{\mathrm{TNT}-\text { casalIR }}\right)^{1 / 3}}
\end{aligned}
$$

If $P_{\text {rupt }}>P_{\mathrm{C}}$

$$
\begin{aligned}
& m_{\mathrm{TNT} \text {-casalIR }}=0.214 e^{-3} 0.05 m_{\mathrm{tot}} \mathrm{SE} \\
& \bar{R}_{\text {casalIR }}=\frac{r}{\left(m_{\mathrm{TNT}-\text { casalIR }}\right)^{1 / 3}}
\end{aligned}
$$

Find the overpressure by using $\bar{R}_{\text {casallR }}$ in Figure A1. 


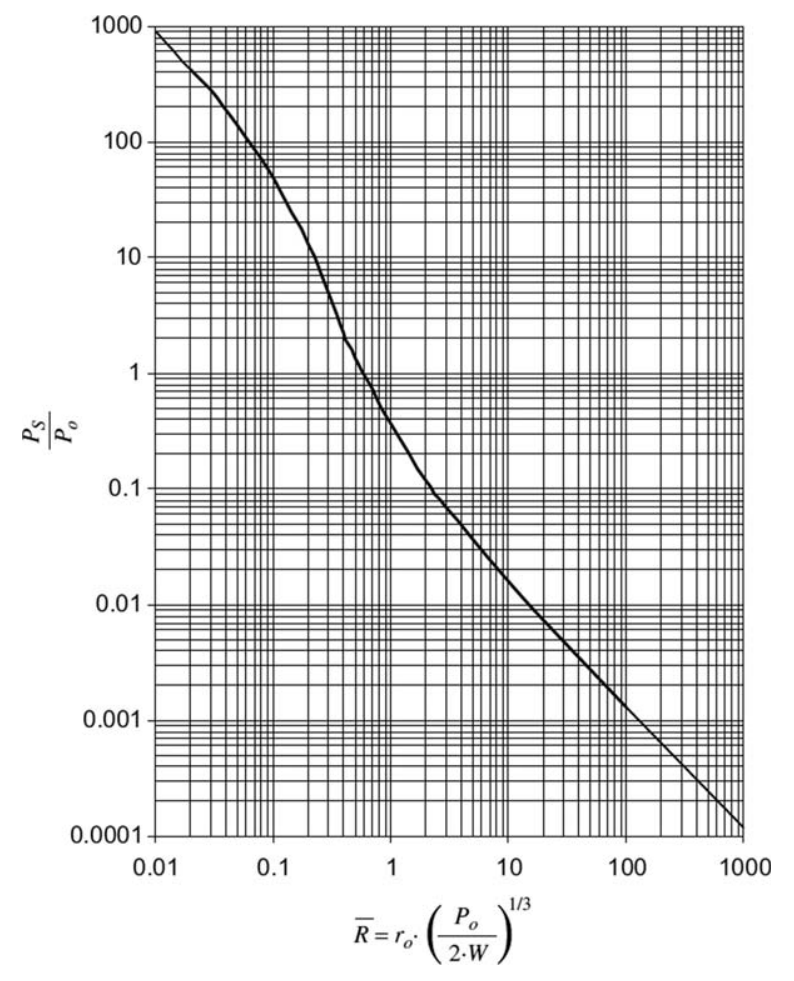

Figure A2. Overpressure versus Sach's scaled distance [8].

\section{Model of Birk (2007) [5]}

$E_{\mathrm{Birk}}=m_{\mathrm{v}}\left(u_{\mathrm{v} 1}-u_{\mathrm{v} 2}\right)$, considering isentropic expansion

$$
\begin{gathered}
m_{\mathrm{Birk}}=2 \cdot 0.214 e^{-3} \cdot E_{\mathrm{Birk}} \\
\bar{R}_{\text {Birk }}=\frac{r}{\left(m_{T N T-\text { Birk }}\right)^{1 / 3}} \\
\frac{P_{\mathrm{S}}}{P_{\mathrm{atm}}}=\frac{808\left[1+\left(\frac{m_{\mathrm{TNT}-\mathrm{Birk}}}{4.5}\right)^{2}\right]}{\sqrt{1+\left(\frac{m_{\mathrm{TNT}-\text { Birk }}}{0.048}\right)^{2}} \sqrt{1+\left(\frac{m_{\mathrm{TNT}-\text { Birk }}}{0.32}\right)^{2}} \sqrt{1+\left(\frac{m_{\mathrm{TNT}-\mathrm{Birk}}}{1.35}\right)^{2}}}
\end{gathered}
$$

\section{Model of TNO (1997) [6]}

$E_{\mathrm{TNO}}=m_{1}\left(u_{11}-u_{12}\right)+m_{\mathrm{v}}\left(u_{\mathrm{v} 1}-u_{\mathrm{v} 2}\right)$, considering isentropic expansion

$$
\bar{R}_{\mathrm{TNO}}=r\left(\frac{100 P_{\mathrm{atm}}}{2 E_{\mathrm{TNO}}}\right)^{1 / 3}
$$

If $\bar{R}_{\mathrm{TNO}}>2$, find overpressure by using $\bar{R}_{\mathrm{TNO}}$ in Figure A2 If $\bar{R}_{\mathrm{TNO}}<2$, find $P_{\mathrm{s} 0}$ the peak shock overpressure directly after the burst

$$
\begin{gathered}
a_{\mathrm{p}} / a_{\mathrm{a}}=\sqrt{\frac{\gamma_{\mathrm{p}} T_{\text {rupt }} \mu_{\mathrm{a}}}{\gamma_{\mathrm{a}} T_{\mathrm{atm}} \mu_{\mathrm{p}}}} \\
\frac{P_{\mathrm{rupt}}}{P_{\mathrm{atm}}}=\left(P_{\mathrm{s} 0}+1\right)\left[1-\frac{(\gamma-1)\left(a_{\mathrm{a}} / a_{\mathrm{p}}\right) P_{\mathrm{s} 0}}{\sqrt{2 \gamma_{\mathrm{a}}\left(2 \gamma_{\mathrm{a}}+\left(\gamma_{\mathrm{a}}+1\right)\right) P_{\mathrm{s} 0}}}\right]^{-2 \gamma /(\gamma-1)} \\
r_{\mathrm{s} 0}=0.782 V_{v}^{1 / 3} \\
R_{\mathrm{s} 0}=r_{\mathrm{s} 0}\left(\frac{100 P_{\mathrm{atm}}}{E}\right)^{1 / 3}
\end{gathered}
$$

Use the curve the closest to the point $\left(R_{s 0}, P_{s 0}\right)$ in Figure A3.

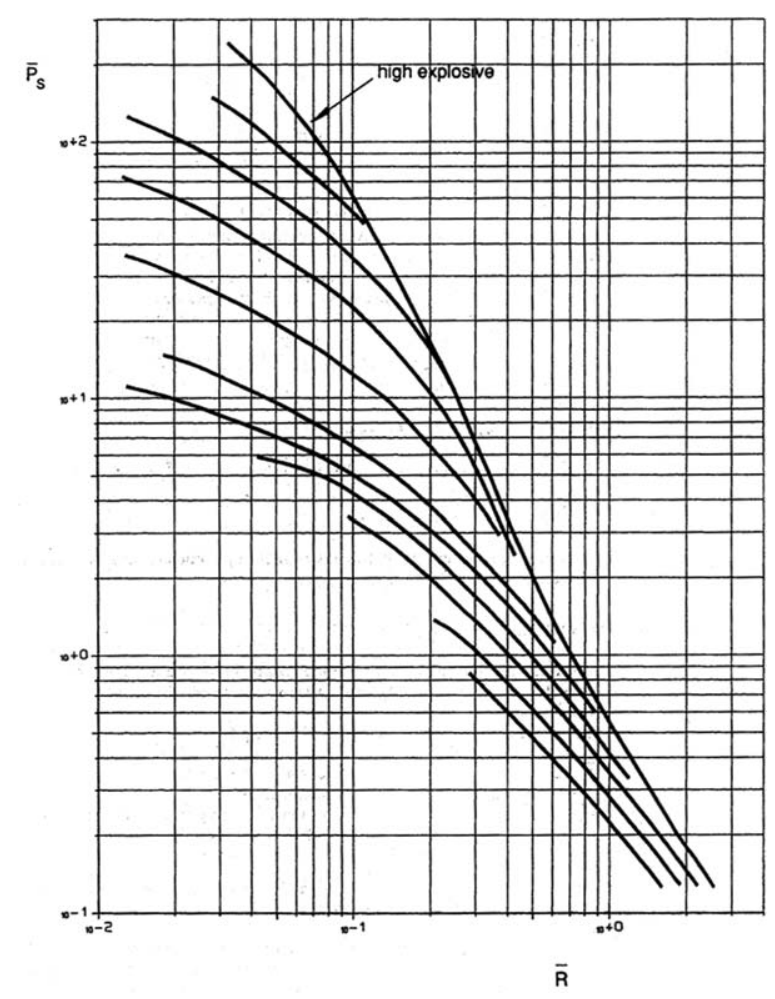

Figure A3. Overpressure versus Sach's scaled distance (to use if $R<2$ ) [6].

\section{Model of Roberts (1999) [7]}

$$
\begin{gathered}
x_{\mathrm{l} 2}=\frac{\left(s_{11}-s_{\mathrm{l} 2}\right)}{\left(s_{\mathrm{v} 2}-s_{\mathrm{l} 2}\right)}, x_{\mathrm{v} 2}=\frac{\left(s_{\mathrm{v} 1}-s_{\mathrm{l} 2}\right)}{\left(s_{\mathrm{v} 2}-s_{\mathrm{l} 2}\right)} \\
m_{\mathrm{l} 2}=\left(1-x_{\mathrm{l} 2}\right) m_{1}+\left(1-x_{\mathrm{v} 2}\right) m_{\mathrm{v}} \\
m_{v 2}=x_{l 2} m_{l}+x_{v 2} m_{v} \\
E_{\text {Roberts }}=\left(m_{\mathrm{l} 2} u_{\mathrm{l} 2}+m_{\mathrm{v} 2} u_{\mathrm{v} 2}-m_{11} u_{\mathrm{l} 1}-m_{\mathrm{v} 1} u_{\mathrm{v} 1}\right) \\
\bar{R}_{\text {Roberts }}=r\left(\frac{100 P_{\mathrm{atm}}}{2 E_{\text {roberts }}}\right)^{1 / 3}
\end{gathered}
$$

Find the overpressure by using Figure A2.

\section{Model of Genova (2008) [8]}

$$
\begin{gathered}
C_{\mathrm{p}}=0.5\left(C_{\mathrm{p}}\left(T_{\text {rupt }}\right)+C_{\mathrm{p}}\left(T_{\mathrm{b}}\right)\right) \\
E_{\text {Genova }}=\left\{\begin{array}{l}
0.07 m_{\mathrm{l}} C_{\mathrm{p}}\left(T_{\text {rupt }}-T_{\mathrm{b}}\right) \text { if } P_{\text {rupt }}<P_{\mathrm{c}} \\
0.07 m_{\mathrm{tot}} C_{\mathrm{p}}\left(T_{\text {rupt }}-T_{\mathrm{b}}\right) \text { if } P_{\text {rupt }}>P_{\mathrm{c}}
\end{array}\right. \\
\bar{R}_{\text {Genova }}=r\left(\frac{100 P_{\text {atm }}}{2 E_{\text {Genova }}}\right)^{1 / 3}
\end{gathered}
$$

Find the overpressure by using $\bar{R}_{\text {Genova }}$ in Figure A2.

\section{ACKNOWLEDGEMENTS}

The authors thank the CEA of Gramat which is supporting this study and collaborating with the von Karman Institute and the Ecole des Mines d'Alès in this joint research project about source term characterization in major hazards. The authors also thank Prof. A.M. Birk for his help that led to a better understanding of the overpressure modeling and a 
correct analysis of his data, and M. Johnson that kindly provided additional large scale measurements results.

\section{LITERATURE CITED}

1. Center for Chemical Process Safety, Guidelines for Vapor Cloud Explosions, Pressure Vessel Burst, BLEVE and Flash Fires hazards, 2nd Ed., Wiley: New York 2010.

2. D. Laboureur, F. Heymes, L. Aprin, P. Rambaud, and J.M. Buchlin, BLEVE overpressure: Small Scale Experiments and Multi-Scale Comparison with Literature Survey of Blast Wave Modeling, 8th Global Congress on Process Safety, Houston, TX, April 1-4. 2012.

3. W.E. Baker, P.A. Cox, P.S. Westine, J.J. Kulesz, and R.A. Strehlow, Explosion hazards and evaluation, Elsevier, Amsterdam, 1983.

4. D.M. Johnson, M.J. Pritchard, and M.J. Wickens, Large scale experimental study of BLEVE: Contract report on CEC COfunded research project, Contract report I5367, Project M8411, British Gas: Research \& Technology division, 1991.

5. A.M. Birk, C. Davison, and M. Cunnigham, Blast overpressure from medium scale BLEVE tests, J Loss Prev Process Ind 20 (2007), 194-206.

6. Committee for the Prevention of Disasters, Methods for the calculation of physical effects due to releases of hazardous materials (liquids and gases)_Yellow Book, CPR14E (2 volumes), 3rd Ed., The Hague (Netherlands) 1997.

7. M.W. Roberts, Analysis of Boiling Liquid Expanding Vapor Explosion (BLEVE) Events at DOE sites, Safety
Analysis Working Group (SAWG) Workshop, April 28May 4, 2000.

8. B. Genova, M. Silvestrini, and F.J. Trujillo, Evaluation of the blast wave overpressure and fragment initial velocity for a BLEVE event via empirical correlations derived by a simplified model of released energy, J Loss Prev Process Ind 21 (2008), 110-117.

9. R. Prugh, Quantitative evaluation of BLEVE hazards, J Fire Protect Eng 3 (1991), 9-24.

10. E. Plana-Cuchi, J.M. Salla, and J. Casal, Calculating overpressure from BLEVE explosions, J Loss Prev Process Ind 17 (2004), 431-436.

11. J. Casal and J.M. Salla, Using liquid superheating energy for a quick estimation of overpressure in BLEVEs and similar explosions, J Hazard Mater 137 (2006), 1321-1327.

12. J. Stawczyk, Experimental evaluation of LPG tank explosion hazards, J Hazard Mater 93 (2003), 189-200.

13. H. Miyamoto, K. Watanabe, A thermodynamic property model for fluid phase propane, Int J Thermophys 21 (2000), 1045-1072.

14. C. Balke, W. Heller, R. Konersmann, and J. Ludwig, Study of the failure limits of a railway tank car filled with liquefied petroleum gas subjected to an open pool fire test, BAM project 3215, Federal Institute for Materials Research and Testing (BAM), 1999.

15. M. Silvestrini, B. Genova, and F.J. Trujillo, Energy concentration factor, a simple concept for the prediction of blast propagation in partially confined geometries, J Loss Prev Process Ind 22 (2009), 460-465. 